\title{
Level of Knowledge in Patients with Type 2 Diabetes Mellitus and its Relationship with Glycemic Levels and Stages of Grief According to Kübler-Ross
}

\author{
Lourdes C. Carrillo-Alarcón ${ }^{1,2 \star}$ Erika López-López ${ }^{1}$, Mario J. López-Carbajal ${ }^{1,2}$, Mario I. Ortiz², Héctor A. Ponce-Monter ${ }^{2}$, Eduardo \\ Fernández-Martinez ${ }^{2}$ and Moisés Ocampo-Torres ${ }^{1,2}$
}

${ }^{1}$ Directorate Coordination of Health Research Health Services Hidalgo, Mexico

${ }^{2}$ Academic Area of Medicine, The Autonomous University of Hidalgo State, Hidalgo, Mexico

\begin{abstract}
Objective: To identify the level of knowledge of Type 2 Diabetes Mellitus (T2DM) in patients assigned to the of diabetes clinics of the Health Services of the state of Hidalgo, Mexico and its relationship with the glycemic level and stages of grief according to Kübler- Ross.

Materials and methods: A cross-sectional study was performed in 310 patients with T2DM from the Diabetes Clinics of the Health Services of Hidalgo that belong to the Mutual Help Group (GAM, for its initials in Spanish). The patients were given the Diabetes Knowledge Questionnaire (DKQ 24); later a fasting venous blood glucose sample was taken and an interview (analysis of content) performed in order to identify their stage of grief. For data analysis, descriptive statistics, the chi square test, and odds ratio were used.

Results: Of the total, $74.2 \%$ were women, $37.4 \%$ were illiterate and $27.1 \%$ had an elementary level education; mean age was $59 \pm 11.3$ years; $71.6 \%$ were housewives; the mean time of evolution of T2DM was $10.4 \pm 6.8$ years. The mean glycemic level was $162.4 \pm 74.5 \mathrm{mg} / \mathrm{dl}$. The score of the DKQ 24 was basic knowledge $5.4 \pm 1.9$, glycemic control $5.4 \pm 2.4$, complications $7.1 \pm .5$ and global $5.9 \pm 1.5$. It was observed that $80.6 \%$ did not identify symptoms of hypoglycaemia and $50.3 \%$ of hyperglycemia; $90.3 \%$ of patients did not know vasculopathy prevention measures. Those who were in acceptance had better control of their glycemic levels than those who were in depression or denial $(P<0.05)$

Conclusion: The level of knowledge of diabetic patients regarding their disease was low. Because of these results it is important to evaluate the subject content of diabetes education courses and offer grief counselling to provide specific coping skills and support.
\end{abstract}

Keywords: Diabetes education; Grief; Health services; Mexico; Level of Knowledge in Patients with Type 2 Diabetes Mellitus

\section{Introduction}

Diabetes Mellitus (DM) represents a challenge to health systems. The growing global epidemic of type $2 \mathrm{DM}$ is expected to increase from 171 million cases in 2000 to 366 million by 2030 [1]. In Mexico, the prevalence was $14.42 \%$ ( 7.3 million diabetics) [2]. By the year 2025 , close to 11.7 million Mexicans are expected to be diagnosed with DM. Although prevention and care policies exist, diabetes continues to be a global public health problem with serious consequences and a high social and economic cost [3]. A patient with DM, due to the chronic nature of the disease, needs to be in permanent contact with health services through programs that use a systematic focus of care that includes more than just the clinic, something that has been termed in recent years "disease management". The usual way to evaluate the quality of type 2 diabetes mellitus (T2DM) control programs is by monitoring clinical indicators, such as HbAlc, LDL cholesterol, arterial blood pressure, microalbuminuria, and DM education [4,5]. The multiple proposals of integral care emphasize DM education. However, it has not had the expected impact because some of the barriers that prevent patients from controlling their disease are unknown.

Patient adherence and knowledge of DM, in addition to culture and language abilities, which influence the patient's health beliefs, attitudes, and health literacy, affect diabetes self-management. Other influential factors include the patient's financial resources, co-morbidities, and social support. The clinician's attitude, beliefs and knowledge of DM also influences diabetes management. Clinicians may further influence the patient's perception through effective communication skills and having a well-integrated healthcare system. Identifying barriers to DM management is necessary to improve the quality of diabetes care, including the improvement of metabolic control, and diabetes selfmanagement [6].

It is important to look for factors that affect appropriate adherence to treatment and this is possibly related to a process of non-elaborated grief. When the patient realizes that DM will not disappear, he and his/her family face the loss of real and imaginary objects, making them change their lifestyle. Although the loss process is constant in their everyday lives, the realization of the presence of DM causes the patient to confront more evident fears of possible losses, such as loss of visual acuity and the presence of peripheral arterial disease, leading to blindness or amputations. These individuals pass through a pattern of

*Corresponding author: Lourdes Cristina Carrillo Alarcón, Research Division of Health Services Hidalgo, Av. México Núm. 300 Col. Villa Aquiles Serdán, Pachuca, Hidalgo, Mexico, C.P. 42039, Tel: +52 771718 0770; E-mail: clourdes.carrillo@yahoo.com.mx

Received November 20, 2014; Accepted January 29, 2014; Published February 15,2015

Citation: Carrillo-Alarcón LC, López-López E, López-Carbajal MJ, Ortiz MI, PonceMontern HE, et al. (2015) Level of Knowledge in Patients with Type 2 Diabetes Mellitus and its Relationship with Glycemic Levels and Stages of Grief According to Kübler-Ross. J Diabetes Metab 6: 495. doi:10.4172/2155-6156.1000495

Copyright: ( 2015 Carrillo-Alarcón LC, et al. This is an open-access article distributed under the terms of the Creative Commons Attribution License, which permits unrestricted use, distribution, and reproduction in any medium, provided the original author and source are credited. 
Citation: Carrillo-Alarcón LC, López-López E, López-Carbajal MJ, Ortiz MI, Ponce-Montern HE, et al. (2015) Level of Knowledge in Patients with Type 2 Diabetes Mellitus and its Relationship with Glycemic Levels and Stages of Grief According to Kübler-Ross. J Diabetes Metab 6: 495. doi:10.4172/2155-6156.1000495

Page 2 of 5

emotional reactions that are similar to the reactions of grief. According to Kubler-Ross, the stages of grief begin with denial, rage, depression, negotiation, and finally acceptance. Once the patient has recognized his/her grief, the process of acceptance comes first, although some prefer the term "adapting to the disease".

DM education includes information, integral counselling regarding the disease, its treatment and complications. It also requires a space where the patient can express his/her feelings and receive emotional support.

Adaptation is a complex process that requires personal mechanisms and individuals who provide emotional support; in this way the patient can acquire power over the disease, and with this, have a better quality of life.

Health services have the responsibility of evaluating the patients' level of knowledge of T2DM, analysing the content and the way information is provided, and the means of taking decisions to improve the quality of care.

The aim of this study is to identify the level of knowledge of diabetes mellitus (DM) in patients with T2DM in the diabetes clinics of the Health Services of Hidalgo, and determine its relationship with glycemia levels and the stage of grief according to Kübler- Ross.

\section{Methods}

A cross-sectional study was conducted in a low-income population from a rural area of the state of Hidalgo, Mexico. The study subjects were patients previously diagnosed with T2DM in treatment who attend the diabetes clinics of the health services of Hidalgo. The sample size was calculated in order to be representative for this population bearing in mind data from prevalence studies carried out in the area, assuming a confidence interval of $95 \%$ and an accuracy level that would only accept a difference of 0.05 . The sample size was estimated at 282 patients but, assuming a $10 \%$ level of missing data, we aimed to recruit 310 patients.

This study was approved by the ethics and research committee of the Board of Health (Health Services of Hidalgo, Mexico). Patients having T2DM were randomly selected from a census of the DM clinic from 12 sanitary jurisdictions of Hidalgo, Mexico. They were recruited between January and February, 2010. The local medical team was in charge of locating each of the selected patients and explaining what the study, and their participation, consisted of, giving them dates for the day of their evaluation and the conditions in which they should come, such as fasting, medication and going with a relative. When a person agreed to participate in the study, he/she signed a written informed consent before starting the survey according to Standard Operating Procedures, Good Clinical Practice, and national regulations.

DM clinics base their care on the Stages of Change model and Mutual Help Groups included within their care. These groups collaborate with the physician in the education of a patient with any chronic disease. In this group we can also find patients with arterial hypertension and metabolic syndrome. The strategy is based on monthly sessions, where information is provided on medical, pharmacological, and diethygienic aspects, as well as providing emotional support in pairs.

The inclusion criteria were as follows: individuals 18 years of age or more, diagnosed with type $2 \mathrm{DM}$, who were currently using insulin, oral hypoglycemic agents or diet, understood the questions on the DKQ-24 questionnaire, and signed the written informed consent.

The DKQ-24 is a valid and reliable instrument that evaluates the knowledge related to DM. It has an alpha Cronbach of 0.78 , is relatively easy to administer, and is validated in Mexican population. The aspects to evaluate include basic information (10 items) glycemic control (7 items) and prevention of complications ( 7 items). It has three response options (yes, no, I don't know). The answer is considered correct when the item is answered appropriately ( 1 correct, 0 incorrect) [7]. A cutoff point of 8.5 was considered "sufficient knowledge" by researcher consensus. A fasting venous blood glucose sample was then taken in all subjects by trained staff. Finally, a semi-structured interview was given to identify at which stage of grief patients were by a thanatologist physician and a psychologist who determined the stage of grief.

According to Kübler-Ross, emotional reactions exist due to a loss [8]. We identified the five stages through which a patient can pass in a short period of time:

\section{Denial}

Denial is a defence mechanism that manifests itself as a conscious or unconscious rejection to facts, information, and the reality related with the situation at hand. It can be observed when the patient does not follow treatment, and the diet, and the patient keeps the same lifestyle.

\section{Anger}

The patient manifests anger toward himself, relatives, partners, medical personnel, health system or symbolic elements (God, divine punishment).

\section{Pact or Negotiation}

This aspect is characterized by trying to pact a truce with life, with the people or the symbolic elements due to the pain or suffering that he/she is feeling and the inability to deal with it. The patient can be condescending due to his/her feelings of guilt for his emotional reactions and the damages he/she could have caused during his/her transition from previous stages.

\section{Depression}

The patient experiments intense states of sadness, and uncontrolled crying. $\mathrm{He} / \mathrm{she}$ socially retracts and isolates him/herself. In this stage, he/she manages to feel real pain and the meaning of the disease; this is why it is important, during this stage, for the patient to be able to express his/her emotions without judgment or criticism.

\section{Acceptance}

In general terms, this stage is an indication that there is acknowledgement of the reality, and an objective attitude toward the diagnosis. The patient recovers his/her mood, accepts the disease as part of life and incorporates treatment into his/her everyday activities and functions. The elaboration of grief includes going through all these stages until they achieve acceptance.

\section{Statistical analysis}

Data was entered into an Access for Windows database (Version 2.6), and OpenEpi version 3.01 was used for all statistical analyses. Patient characteristics were summarized as means with standard deviations for continuous variables and as numbers with valid percentages for categorical variables. We used the chi-square test, Student's t test and odds-ratio with a 95\% confidence interval for the data analyzed. The level of statistical significance was $\mathrm{P} \leq 0.05$.

\section{Results}

Of the total population, $74.2 \%$ were women; $37.4 \%$ were illiterate, 
Citation: Carrillo-Alarcón LC, López-López E, López-Carbajal MJ, Ortiz MI, Ponce-Montern HE, et al. (2015) Level of Knowledge in Patients with Type 2 Diabetes Mellitus and its Relationship with Glycemic Levels and Stages of Grief According to Kübler-Ross. J Diabetes Metab 6: 495. doi:10.4172/2155-6156.1000495

Page 3 of 5

$27.1 \%$ had an elementary school, $23.2 \%$ middle school, $5.2 \%$ preparatory and $7.1 \%$ a university level or more; mean age was 59 years; the time of evolution of DM was 10.4 years; $73.9 \%$ had a glycemia higher than $110 \mathrm{mg} / \mathrm{dL}$ and with regard to occupation, $71.6 \%$ were housewives; $87.7 \%$ received healthcare at the Health Services of Hidalgo, $0.3 \%$ at the Mexican Institute of Health Services, $0.3 \%$ at the Institute for Social Security and Services for State Workers, and $11.7 \%$ attended private services and other. Patients received information about diabetes from a physician, $76.1 \%$, from a nurse, $10.7 \%$ and from others $13.9 \%$. The stage of grief was denial in $32.9 \%$, anger in $10 \%$, pact or negotiation in $0.7 \%$, depression in $43.9 \%$, and acceptance in $2.6 \%$.

The physician's attitude was perceived by the patient as null assertiveness in $50.2 \%$, low assertiveness in $21.5 \%$, middle assertiveness in $15.9 \%$, high assertiveness in $2.7 \%$, and excellent assertiveness in $9.6 \%$.

Regarding the DKQ-24, it was divided into basic information, glycemic control, and complications. The cutoff was established by consensus at 8.5 on a scale of 0 to 10 . The score was basic knowledge 5.44; glycemic control 5.4, complications 7.1, and global knowledge 5.9 (Table 1).

The correlation between the DKQ24 score and the level of education showed an $\mathrm{R}$ squared $=0.169(\mathrm{P}<0.000)$. Glucose and knowledge level showed no association. Table 2 shows that $64.5 \%$ of the diabetic patients had an elementary school level and were illiterate with an OR of 2.45 (P $=0.0373$ ). Those who belong to the GAM, had a 6.2 -fold possibility of increasing their level of knowledge $(\mathrm{P}=0.0318)$.

Of the total, $76.1 \%$ reported that they received more information about their diabetes from their physicians. Those who mentioned this, had a 0.3 -fold greater likelihood of increasing their level of knowledge $(\mathrm{P}=.012) ; 46.8 \%$ of physicians had null assertiveness and only $9.0 \%$ excellent assertiveness. When the physicians' attitude was excellent or there was high assertiveness (Table 2), patients had a 4.5 -fold greater possibility of increasing their level of knowledge $(\mathrm{P}=0.002)$.

\begin{tabular}{|c|c|c|c|c|}
\hline Variable & Population, $n=310$ & Knowledge Level $\geq 8.5$ n=16 & Knowledge Level<8.5, n=294 & $P$ value \\
\hline Age (years) & $59 \pm 11.3(29-88)$ & $57.1 \pm 4.9(53.0-67)$ & $59.1 \pm 11.4(29-88)$ & 0.0382 \\
\hline Years with T2DM & $10.4 \pm 6.8(0-35)$ & $10.1 \pm 8.3(2.0-28)$ & $10.4 \pm 6.7(0-35)$ & 0.1839 \\
\hline Years within Mutual Help Group & $3.8 \pm 3.5(0.5-20)$ & $4.5 \pm 4.3(0.5-16)$ & $3.8 \pm 3.4(0.5-20)$ & 0.152 \\
\hline Blood glucose (mg/dl) & $162.4 \pm 74.5(60-490)$ & $122.1 \pm 39.9(83.0-208)$ & $164.6 \pm 75.3(60-490)$ & 0.0066 \\
\hline Basic knowledge & $5.4 \pm 1.9(1-10)$ & $8.4 \pm 1.4(6.0-10)$ & $5.2 \pm 1.7(1-10)$ & 0.3887 \\
\hline Knowledge about control & $5.4 \pm 2.4(0-10)$ & $9.4 \pm 0.7(8.6-10)$ & $5.2 \pm 2.2(0-10)$ & 0.0000 \\
\hline Knowledge about complications & $7.1 \pm 1.5(0-10)$ & $8.5 \pm 0.8(7.1-10)$ & $6.9 \pm 1.4(0-10)$ & 0.0152 \\
\hline General knowledge & $5.9 \pm 1.5(0.3-9.5)$ & $8.7 \pm 0.3(8.5-9.5)$ & $5.7 \pm 1.4(0.3-8.38)$ & 0.0000 \\
\hline
\end{tabular}

T2DM, type 2 diabetes mellitus

Data are presented as means $\pm S D$ (min-max), except $P$ values.

Table 1: Results of diabetes knowledge.

\begin{tabular}{|c|c|c|c|c|c|c|}
\hline & & $\begin{array}{c}\text { Knowledge Level } \\
\geq 8.5\end{array}$ & $\begin{array}{l}\text { Knowledge } \\
\text { Level }<8.5\end{array}$ & & & \\
\hline & n (\%) & Sufficient (\%) & Deficient (\%) & $P$ value & OR & $95 \% \mathrm{Cl}$ \\
\hline \multicolumn{7}{|l|}{ Sex } \\
\hline Men & $80(25.8)$ & $3(18.8)$ & $77(26.2)$ & 0.508 & 0.7 & $0.18-2.3$ \\
\hline Women & $230(74.2)$ & $13(81.3)$ & $217(73.8)$ & & & \\
\hline \multicolumn{7}{|l|}{ Occupation } \\
\hline Employee & $88(28.4)$ & $4(25)$ & $84(28.6)$ & 0.758 & 0.833 & $0.261-2.657$ \\
\hline Housewife & $222(71.6)$ & $12(75)$ & $210(71.4)$ & & & \\
\hline \multicolumn{7}{|l|}{ Education } \\
\hline Secondary school and more & $110(35.484)$ & $9(56.3)$ & $101(34.4)$ & 0.03732 & 2.457 & $0.889-6.79$ \\
\hline Elementary school and illiteracy & $200(64.516)$ & $7(43.8)$ & $193(65.6)$ & & & \\
\hline \multicolumn{7}{|l|}{ Healthcare institution } \\
\hline Hidalgo Health Services & $272(87.7)$ & $15(93.8)$ & $257(87.4)$ & 0.452 & 0.463 & 0.059-3.609 \\
\hline Other & $38(12.3)$ & $1(6.3)$ & $37(12.6)$ & & & \\
\hline \multicolumn{7}{|l|}{ Belongs to a Mutual Help Group } \\
\hline Yes & $223(71.9)$ & $16(100)$ & $207(70.4)$ & 0.0318 & 6.281 & $1.095-135.5$ \\
\hline No & $87(28.1)$ & $0(0.0)$ & $87(29.6)$ & & & \\
\hline \multicolumn{7}{|c|}{ Who they received more information about diabetes from } \\
\hline Physician & $236(76.1)$ & $8(50.0)$ & $228(77.6)$ & 0.012 & 0.289 & $0.105-0.801$ \\
\hline Other & $74(23.9)$ & $8(50.0)$ & $66(22.5)$ & & & \\
\hline \multicolumn{7}{|l|}{ Stage of grief } \\
\hline Acceptance & $39(12.6)$ & $5(31.2)$ & $34(11.6)$ & 0.0044 & 3.863 & $1.33-11.22$ \\
\hline Other & $271(87.4)$ & $11(68.8)$ & $260(88.4)$ & & & \\
\hline \multicolumn{7}{|l|}{ Physician's attitude } \\
\hline Excellent or high assertiveness & $74(23.9)$ & $9(56.3)$ & $65(22.11)$ & 0.002 & 4.5 & $1.625-12.63$ \\
\hline Middle, low or null assertiveness & $236(76.1)$ & $7(43.8)$ & $229(77.89)$ & & & \\
\hline
\end{tabular}

Table 2: Diabetes knowledge and patient characteristics. 
Citation: Carrillo-Alarcón LC, López-López E, López-Carbajal MJ, Ortiz MI, Ponce-Montern HE, et al. (2015) Level of Knowledge in Patients with Type 2 Diabetes Mellitus and its Relationship with Glycemic Levels and Stages of Grief According to Kübler-Ross. J Diabetes Metab 6: 495. doi:10.4172/2155-6156.1000495

Page 4 of 5

Of the $71.9 \%$ that belonged to a GAM, only $7.2 \%$ had an adequate score in the DKQ-24. The mean time they had been in the GAM was 3.8 years with a range of 0.5 to 20 years. The mean blood glucose level was less than $122.1 \mathrm{mg} / \mathrm{dL}$ in those who had sufficient knowledge of the disease $(\mathrm{P}=0.0066)$ and who were in the younger group.

According to stage of grief, only $2.6 \%$ were in the acceptance stage and had a 3.9- fold possibility of increasing their knowledge $(\mathrm{P}=0.0044)$. Also, those in acceptance had better control of their glycemia than those who were in denial or depressed $(\mathrm{P}<0.05)$ (Figure 1$)$.

It was found that $80.6 \%$ could not identify symptoms of hypoglycemia, and $50.3 \%$ of hyperglycemia; $90.3 \%$ had no knowledge of vasculopathy prevention measures, despite their knowledge about the importance of cutting their toenails with care and the damage to their kidneys caused by diabetes ( $96.5 \%$ and $94.8 \%$, respectively).

\section{Discussion}

The questions with the lowest scores were related to the etiology of DM, since patients believed that it was due to a high consumption of sugar or sweet foods. We also found very little knowledge about questions related to pathophysiology. In glycemic control, metabolic signs and symptoms were unknown and could put the patient's life at risk. Finally, regarding complications, solid knowledge of care to prevent them did not exist.

Our results are similar to those reported in literature in relation to women more frequently attending health services; although, in other studies, it has been found that beliefs by gender influence DM control and diet [9]. Likewise, the education level is low and individuals had scarce knowledge about their disease, with more notions of chronic complications.

Regarding the level of knowledge, we found that less than $20 \%$ of the patients have an adequate understanding of the disease. Regarding self-care in the prevention of diabetes complications, there was a slightly higher percentage. The results of the DKQ-24 show that even though people had been in the GAM for 15 years, they did not have the knowledge to provide their peers with the skills to change their lifestyle. It is relevant that although they belong to the GAM, the majority of patients do not recognize any of the signs of hypoglycemia

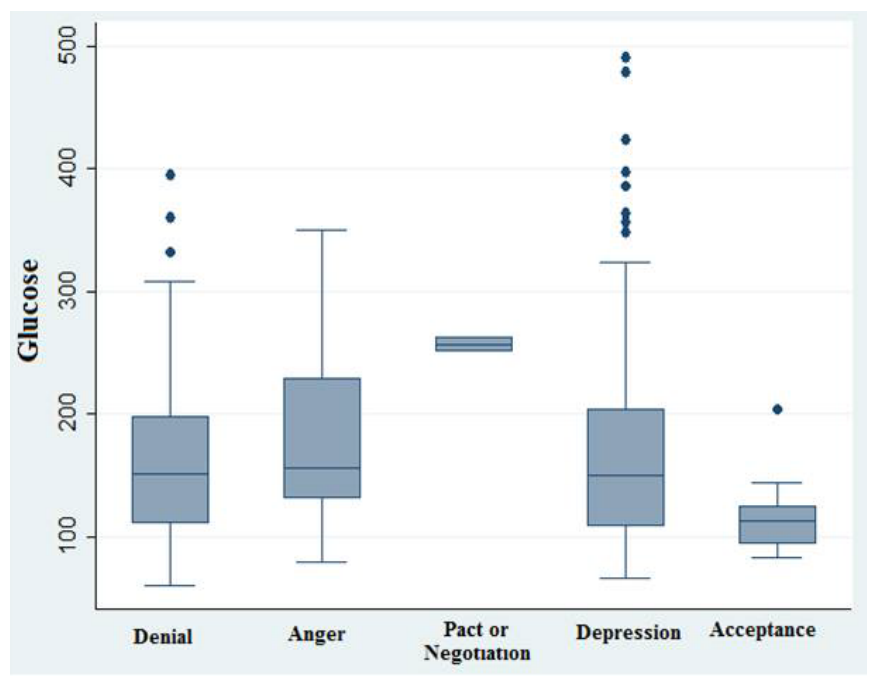

Figure 1: Relationship between stage of grief and glucose levels. or hyperglycemia and continue with misbeliefs about the origin of DM. Regarding the results of education level on the DKQ-24, these show that illiteracy is directly associated with a low level of knowledge of DM; therefore it would be important to analyse if the content and the way information is provided are adequate and effective for this population. Also, it is important to consider other factors such as habits, food preferences, values, beliefs, teaching strategies, level of education, and the number of participants per group. One of the limitations of the study is that the content and educational strategies used by the GAM are unknown.

It is noteworthy that the prevention of complications is best known by patients, which is in accordance with information mentioned by Bautista in a Mexican population [10]. Patients with diabetes have frequently experienced the diabetes complications of their relatives and it is through these experiences that they learn more about their future as an individual with diabetes.

The performance effectiveness of the biological indicators of some of the educational interventions in DM is due in great part to the incorporation of cultural aspects.

It shows that it is important to consider that some patients feel threaten by the demand of treatment, its control and the new lifestyle, which represent a social and cultural challenge in the adaptation process. That is why unconsciously they do not follow recommendations.

These demands can also be reflected in not following the hygienic measures they need in their everyday lives since being diagnosed. For example in this case, $83.2 \%$ of the studied patients did not know the importance of these measures. For this accomplishment, it is also important to consider the economic barriers when the health system cannot provide them with support.

Inadequate information was found regarding the practice of physical activity. The fear of hypoglycemia is one of the principal obstacles reported for physical activity in these patients; $49.3 \%$ reported that regular exercise increases the need for insulin or other drugs.

Some health professionals have identified a lack of adherence to treatment with denial of the sickness and this can be an obstacle for the patient to overpower the disease [11]. Some studies show us that non-adherence is associated with exercise and poor mobility, self- care, usual activities, pain and anxiety [12].

Everyday losses are present in our lives. Some people do not achieve to elaborate each one of these stages and develop a pathological duel. When diagnosed with DM, the patient faces symbolic losses such as the loss of their health and their lifestyle. If the patient does not elaborate grief, he/she can deny the existence of the disease, present a depressive syndrome and have constant anger. This process is dynamic because the patient does not necessarily remain in a specific stage of grief and can present emotional reactions that take them from one stage to another in simultaneous ways. This prevents them from accepting the disease and following the treatment, diet, physical activity and other recommendations.

For this reason, early detection of depression is essential to improve the course of diabetes [13].

Results indicate that patients who manage to accept their diseasethese being the minority-report a better control of their glycemia, and their level of knowledge is greater than those who find themselves in depression, rage or denial. This helps to show that the information by itself is not sufficient. It is also necessary to deal with the emotions that 
Citation: Carrillo-Alarcón LC, López-López E, López-Carbajal MJ, Ortiz MI, Ponce-Montern HE, et al. (2015) Level of Knowledge in Patients with Type 2 Diabetes Mellitus and its Relationship with Glycemic Levels and Stages of Grief According to Kübler-Ross. J Diabetes Metab 6: 495. doi:10.4172/2155-6156.1000495

Page 5 of 5

detonate a diagnosis and the psychological aspects that develop during grief even if the patient achieves elaboration. Health professionals require sensitivity and ability to help them in this process.

Studies report serious deficiencies in the information that patients and their families receive about DM. Kruse et al. [14] mention that clinicians often focus their communication on quantitative measures such as blood pressure and glycosylated haemoglobin but patients find it difficult to relate these measures to how they are feeling physically. Patients' social context influences their self-management activities, in particular heavy caregiving responsibilities and work schedules. This shows the need for better education in non-traditional fields. Programs need to strengthen education in areas of diet, hyperglycemia, and hypoglycemia symptoms, and the care of injuries.

For the health professional it seems surprising that the patient does not follow the treatment and indications. These reactions often can be understood by the emotional adjustments that are taking place. It is estimated that rates of non-adherence to chronic diseases are around $50 \%$. International studies have reported some psychosocial factors related to treatment adherence, low levels of treatment adherence, and high rates of stress in DM2 patients, as well as an association with high levels of glycosylated haemoglobin [15].

The current model for diabetes care education in Mexico is ineffective and a paradigm change is needed [9]. Therapeutic patient education should be a planned and structured program that is comprehensive in scope, flexible in content, responsive to an individual's clinical and psychological needs, and adaptable to patients' educational and cultural background [16].

Few T2DM interventions address emotional wellbeing in Latinos. More care has been directed toward designing culturally sensitive community-based programs for improving behaviour and physical outcomes. Because some Latino groups believe that negative emotions cause diabetes and because depression and anxiety are associated with poor self-management, programs should address emotional wellbeing as an important aspect of diabetes management [17].

We feel that there is a need to understand and study the stages of grief in the T2DM patient so they can understand their disease and obtain beneficial treatment results. For this, physicians need to offer grief counselling to provide specific coping skills and support.

Also, it is important to evaluate the subject content and educational strategies of diabetes education courses.

\section{Conclusions}

There are few studies that assess the relationship between level of knowledge and grief in addition to glycemic control. Patients showed insufficient knowledge of glycemic control and problems in identifying symptoms of hyper and hypoglycemia. This indicates disinformation and possible cultural influences deeply rooted in society. This study demonstrates the scarce knowledge that patients have of the etiology and essential aspects of DM in this population.

Our results show that we need to evaluate the content of the educational programs of the GAM, with emphasis on basic information, control and complications. Due to the main problems regarding treatment such as following the diet, physical activity, and medical care, it is necessary to design a psychological support program for the patients to elaborate their grief so they have better treatment adherence. Public and private medical services need to strengthen these areas to offer integral services and provide the skills for the medical team in order to improve empathy and support in the doctor-patient relationship.

\section{Acknowledgments}

We thank Pharmacist David Chavez-Gallegos for his support; Dr. Marco A García-Martínez and Dr. Marisa Ibarra-Rodríguez, from the Ministry of Health in Hidalgo, for their help.

\section{References}

1. Wild S, Roglic G, Green A, Sicree R, King H (2004) Global prevalence of diabetes: estimates for the year 2000 and projections for 2030. Diabetes Care 27: 1047-1053

2. Villalpando S, Rojas R, Shamah-Levy T, Ávila MA, Gaona B, et al. (2010) Prevalence and distribution of type 2 Diabetes mellitus in Mexican adult population.A probabilistic survey. Salud Publica Mex 52: 19-26.

3. Rull JA, Aguilar-Salinas CA, Rojas R, Rios-Torres JM, Gomez-Perez FJ, et al (2005) Epidemiology of type 2 diabetes in Mexico. Arch Med Res36: 188-196

4. Pimouguet C, Le Goff M, Thiébaut R, Dartigues JF, Helmer C (2011) Effectiveness of disease-management programs for improving diabetes care: a meta-analysis. CMAJ 183: 115-127.

5. Knight K, Badamgarav E, Henning JM, Hasselblad V, Gano A, et al. (2005) A systematic review of diabetes disease management programs. Am J Manag Care 11: 242-250.

6. Nam S, Chesla C, Stotts NA, Kroon L, Janson SL (2011) Barriers to diabetes management: patient and provider factors. Diabetes Res Clin Pract 93: 1-9.

7. Garcia A, Villagomez ET, Brown SA, Kouzekanani K, Hanis CL (2001) Development of the Spanish-language diabetes knowledge questionnaire. Diabetes Care 24: 16-21

8. Kubler-Ross E (2011) Sobre la muerte y los moribundos. Editorial Debolsillo. Mexico.

9. González-Villalpando C López-Ridaura R, Campuzano JC, GonzálezVillalpando ME (2010) The status of diabetes care in Mexican population: Are we making a difference? Results of the National Health and Nutrition Survey 2006. Salud Publica Mex 52: 36-43.

10. Bautista-Martinez S, Aguilar-Salinas CA, Lerman I, Velasco ML, Castellanos R et al. (1999) Diabetes knowledge and its determinants in a Mexican population. Diabetes Educ. 25: 374-381.

11. Debono M, Cachia E (2007) The impact of diabetes on psychological well being and quality of life. The role of patient education. Psychol Health Med. 12: 54555 .

12. Saleh F, Mumu SJ, Ara F, Hafez MA, Ali L (2014) Non-adherence to self-care practices \& medication and health related quality of life among patients with type 2 diabetes: a cross-sectional study. BMC Public Health 14: 431.

13. Pozzo MJ, Mociulsky J, Martinez ET, Senatore G, Farias JM, et al. (2014) Diabetes and Quality of Life: Initial Approach to Depression, Physical Activity and Sexual Dysfunction. Am J Ther.

14. Kruse RL, Olsberg JE, Shigaki CL, Parker Oliver DR, Vetter-Smith MJ, et al. (2013) Communication during patient-provider encounters regarding diabetes self-management. Fam Med 45: 475-483.

15. Ortiz M, Ortiz E, Gatica A, Gómez D (2011) Factores Psicosociales Asociados a la Adherencia al Tratamiento de la Diabetes Mellitus Tipo 2. Terapia psicológica 29: 5-11.

16. Hidvégi T (2011) Patient education: an indispensable element of care of patients with diabetes mellitus. Orv Hetil 152: 1941-1948

17. Concha JB, Kravitz HM, Chin MH, Kelley MA, Chavez N, et al. (2009) Review of type 2 diabetes management interventions for addressing emotional well-being in Latinos. Diabetes Educ 35: 941-958 